\title{
Analisis Akuntabilitas Kerja Pelayanan Kartu Tanda Penduduk (KTP), Kartu Keluarga (KK) dan Perizinan (Studi Kasus di Kantor Camat Badiri Kabupaten Tapanuli Tengah)
}

\author{
Zafril Abdi Nasution
}

STIE Al-Washliyah Sibolga

Jubri Panjaitan

STIE Al-Washliyah Sibolga

\begin{abstract}
Abstrak
Penelitian ini bertujuan untuk mengetahui untuk mengetahui akuntabilitas kerja berpengaruh terhadap pelayanan kartu tanda penduduk (KTP), kartu keluarga (KK) dan perizinan pada Kantor Camat Badiri Kabupaten Tapanuli Tengah. Adapun hipotesis penelitian ini adalah :Akuntabilitas kerja berpengaruh terhadap pelayanan kartu tanda penduduk (KTP), kartu keluarga (KK) dan perizinan pada Kantor Camat Badiri Kabupaten Tapanuli Tengah.

Populasi dalam penelitian ini adalah masyarakat Kecamatan Badiri dan sampel dalam penelitian berjumlah 100 orang. Teknik analisis data yang digunakan dengan pendekatan kualitatif dan kuantitatif.Berdasarkan hasil penelitian terhadap 100 responden, menunjukkan hubungan antara akuntabilitas kerja terhadap pelayanan adalah kuat, dimana koefisien korelasi diperoleh 0,63Hasil perhitungan koefisien determinasi diperoleh 39,69\%. Berdasarkan model regresi linear sederhana yang diperoleh persamaan regresi adalah $\mathrm{Y}=2,50+$ $0,67 \mathrm{x}$ menunjukkan hubungan antaraakuntabilitas kerja terhadap pelayanan kearah yang positif.Berdasarkan uji $t$ diperoleh sebesar 8,09 dan $t_{\text {tabel }}=1,980$, maka dapat dikatakan $t_{\text {hitung }}>$ dari $t_{\text {tabel }}$ dapat ditarik kesimpulan bahwa $\mathrm{H}_{\mathrm{a}}$ dapat diterima. Disarankan dari segi pelayanan publik, hal yang perlu ditingkatkan adalah kualitas yang sudah dibangun untuk menciptakan kepuasan masyarakat dipertahankan dengan sikap ramah pegawai, berpenampilan baik serta mengerti kebutuhan dan menindaklanjuti keluhan yang disampaikan oleh masyarakat. Selain itu pelayanan hendaknya dilakukan secara lebih mudah cepat dan sesuai dengan prosedur dan perundang-undangan yang berlaku.
\end{abstract}

Kata Kunci Akuntatabilitas, Pelayanan KTP, KK, dan Perizinan

\section{PENDAHULUAN}

Gelombang reformasi telah bergulir menuntut perubahan dalam segala tatanan kehidupan 
kenegaraan. Salah satu latar belakang bergulirnya reformasi adalah masyarakat kecewa kepada pemerintah. Pemerintah tidak mampu memberikan pelayanan baik kepada masyarakat. Rakyat sebagai pemilik kedaulatan sudah tidak memiliki haknya lagi.

Hingga sekarang ini kualitas pelayanan publik masih diwarnai berbagai masalah seperti pelayanan yang sulit untuk diakses, prosedur yang berbelit-belit ketika harus mengurus suatu perijinan tertentu, biaya yang tidak jelas, serta terjadinya praktek pungutan liar (pungli), merupakan indikator rendahnya kualitas pelayanan publik di Indonesia. Dimana hal ini juga sebagai akibat dari berbagai permasalahan pelayanan publik yang belum dirasakan eksistensinya oleh rakyat. Menilik dari fungsi utama pemerintah yang merupakan penyelenggara pelayanan publik, seiring dengan tuntutan perkembangan sudah menjadi seharusnya pemerintah melakukan perbaikan dalam pelayanan publik tersebut, akan tetapi dewasa ini, kepercayaan masyarakat/publik terhadap kinerja pemerintah atau birokrasi mengalami degradasi yang kian semakin parah oleh akibat dari lemahnya kinerja aparatur pemerintahan.

Kecamatan Badiri Kabupaten Tapanuli Tengah yang dalam hal ini sebagai pelaksana pelayanan publik yang langsung bersinggungan dengan masyarakat diharapkan mampu menerapkan prinsip-prinsip Good Governance antara lain akuntabilitas dan transparansi. Namun kenyataan di lapangan sering dijumpai adanya berbagai keluhan dari masyarakat atas pelayanan yang diberikan oleh para aparatur pemerintah di kecamatan.

Hal ini juga terjadi di Kecamatan Badiri Kabupaten Tapanuli Tengah. Kurangnya keramahan pegawai dalam pengurusan berbagai keperluan administrasi menyebabkan masyarakat merasa tidak dilayani dengan baik. Selain itu pengurusan kartu tanda penduduk (KTP), kartu keluarga (KK) dan Perizinan, yang seharusnya gratis dan selesai dalam jangka waktu seminggu, tidak terlaksana dengan baik. Pegawai kecamatan terkadang mengutip dana dari masyarakat dalam hal pengurusan KTP dan KK agar cepat siap. Kurangnya transparansi dalam hal biaya administrasi sangat dikeluhkan masyarakat. Masyarakat juga mengeluhkan prosedur dan mekanisme kerja pelayanan yang berbelit-belit, kurang informatif, kurang akomodatif, dan terbatasnya fasilitas, sarana, dan prasarana sehingga tidak menjamin kepastian (hukum, waktu, dan biaya), serta tindakan yang berindikasikan penyimpangan.

Berdasarkan uraian di atas, penulis tertarik untuk mengadakan penelitian tentang Akuntabilitas Kerja terhadap Pelayanan Kartu Tanda Penduduk (KTP), Kartu Keluarga (KK) dan Perizinan (Studi Kasus Pada Kantor Camat Badiri Kabupaten Tapanuli Tengah).

\section{TINJAUAN PUSTAKA}

\section{A. Akuntabilitas}

Dalam Keputusan Menteri PAN Nomor. 63/KEP/M.PAN/8/2013 dikatakan bahwa "Penyelenggaraan pelayanan publik harus dapat dipertanggungjawabkan, baik kepada publik maupun kepada atasan/pimpinan unit pelayanan instansi pemerintah sesuai dengan ketentuan peraturan perundang-undangan."

Menurut Miriam Budiarjo, (2010 : 74) mengartikan akuntabilitas sebagai Pertanggung jawaban pihak yang diberi mandat untuk memerintah kepada mereka yang memberi mandat itu. Akuntabilitas bermakna pertanggung jawaban dengan menciptakan pengawasan melalui distribusi kekuasaan ada berbagai lembaga pemerintah sehingga mengurangi penumpukan kekuasaan sekaligus menciptakan kondisi saling mengawasi.

Selanjutnya Bambang Istianto, (2009: 109) akuntabilitasdiartikan "Setiap tugas dan tangggung jawab pemerintahan daerah harus diselenggarakan dengan baik karena setiap 
kebijakan dan tindakan yang diambil harus dapat dipertanggungjawabkan kehadapan publik maupun dari kacamata hukum."

"Akuntabilitas kinerja instansi pemerintahan adalah perwujudan kewajiban instansi pemerintah untuk mempertanggungjawabkan keberhasilan dan kegagalan pelaksanaan misi organisasi dalam mencapai sasaran dan tujuan yang telah ditetapkan melalui alat pertanggungjawaban secara periodik." (Gambir Bhatta, 2006 : 87).

\section{B. Pelayanan}

Pelayanan diartikan "Sebagai pemberian layanan (melayani) keperluan masyarakat yang mempunyai kepentingan pada organisasi itu sesuai dengan aturan pokok dan tata cara yang telah ditetapkan.'(Sinambela, $2006: 5)$

Sedangkan Boediono (2003 : 60) menyatakan bahwa, pelayanan juga disebut "Suatu proses bantuan kepada orang lain dengan cara-cara tertentu yang memerlukan kepekaan dan hubungan interpersonal agar terciptanya kepuasan dan keberhasilan."

Sesuai dengan Keputusan Menteri PAN Nomor. 63/KEP/M.PAN/8/2013, pelayanan publik dibagi berdasarkan 3 (tiga) kelompok, yaitu :

1. Kelompok pelayanan administratif, yaitu bentuk pelayanan yang menghasilkan berbagai macam dokumen resmi yang dibutuhkan oleh masyarakat atau publik.

2. Kelompok pelayanan barang, yaitu pelayanan yang menghasilkan berbagai bentuk/jenis barang yang digunakan publik.

3. Kelompok pelayanan jasa, yaitu pelayanan yang menghasilkan berbagai bentuk jasa yang dibutuhkan publik

\section{METODE PENELITIAN}

Berdasarkan latar belakang masalah pokok dan hipotesis yang dikemukakan sebelumnya, maka metode analisis yang digunakan untuk pengujian dan pembuktian hipotesis adalah :

1. Analisis kualitatif.

Analisis kualitatif merupakan analisis data yang tidak dapat dinominasikan dengan menggunakan angka, melainkan disajikan berupa keterangan, penjelasan dan pembahasan teori.

2. Analisis kuantitatif.

Analisis kuantitatif adalah analisis data dalam bentuk angka-angka yang pembahasannya, melalui penghitungan statistik berdasarkan jawaban kuesioner dari responden. Hasil penghitungan dari skor atau nilai tersebut kemudian di analisis statistik untuk membuktikan hubungan antara variabel-variabel penelitian, dengan melakukan uji data sebagai berikut :

a. Koefisien korelasi.

Adapun rumus koefisien korelasi Karl Pearson Product Moment (Sugiyono 2012 : 250) untuk mengetahui hubungan kedua variabel tersebut sebagai berikut :

$$
\mathrm{r}_{\mathrm{xy}}=\frac{\mathrm{n} \cdot \Sigma \mathrm{XY}-(\Sigma \mathrm{X}) \cdot(\Sigma \mathrm{Y})}{\sqrt{\left(\mathrm{n} \cdot \Sigma \mathrm{X}^{2}-(\Sigma \mathrm{X})^{2}\right) \cdot\left(\mathrm{n} \cdot \Sigma \mathrm{Y}^{2}-(\Sigma \mathrm{Y})^{2}\right)}}
$$

Keterangan : 
$\mathrm{r}_{\mathrm{xy}}$ : Koefisien korelasi antara $\mathrm{X}$ dan $\mathrm{Y}$

$\mathrm{X}$ : Variabel bebas (pimpinan)

Y : Variabel terikat (kualitas pelayanan publik)

$\mathrm{n}$ : Jumlah sampel

Untuk melihat hubungan kedua variabel tersebut, maka dapat dirumuskan sebagai berikut, :

1) Nilai $r$ yang positif menunjukkan hubungan kedua variabel positif, artinya kenaikan nilai variabel yang satu diikuti oleh nilai variabel $Y$.

2) Nilai $r$ yang negatif menunjukkan hubungan kedua variabel negatif, artinya menurunnya nilai variabel yang satu dengan diikuti meningkatnya nilai variabel yang lain.

3) Nilai $r$ yang sama dengan nol menunjukkan kedua variabel tidak menunjukkan hubungan, artinya variabel yang satu tetap meskipun yang lainya berubah.

Untuk mengetahui adanya hubungan yang tinggi, sedang atau rendah antara kedua variabel berdasarkan nilai $r$ (koefisien korelasi) digunakan penafsiran atau interpretasi angka sebagai berikut :

Tabel 1.Interprestasi Koefisien korelasi Sumber : Sugiyono (2012: 250)

\begin{tabular}{|c|l|}
\hline Interprestasi Koefisien & Tingkat Hubungan \\
\hline $0.80-1.000$ & Sangat kuat \\
$0.60-0.799$ & kuat \\
$0.40-0.599$ & Sedang \\
$0.20-0.399$ & Rendah \\
$0.00-0.199$ & Sangat rendah \\
\hline
\end{tabular}

Setelah nilai $\mathrm{r}$ diperoleh, maka dapat diketahui apakah nilai $\mathrm{r}$ yang diperoleh berarti atau tidak dan bagaimana tingkat hubungannya melalui tabel korelasi. Tabel korelasi menentukan batas-batas $r$ yang signifikan.

b. Koefisien Determinasi.

Teknik ini digunakan untuk mengetahui berapa persen besarnya pengaruh variabel bebas/independen $(\mathrm{X})$ terhadap variabel terikat/ dependen $(\mathrm{Y})$, dilakukan perhitungan koefisien determinant dengan rumus sebagai berikut : $K D=r^{2} \times 100 \%$.

c. Analisis Regresi Linear Sederhana.

Adapun rumus yang digunakan untuk mencari regresi linear sederhana untuk melihat hubungan tersebut signifikan atau tidak dengan menggunakan rumus sebagai berikut:

$$
\mathrm{Y}=\mathrm{a}+\mathrm{bX}
$$

Untuk memperoleh garis regresi dibutuhkan data dari kedua variabel $\mathrm{X}$ dan variabel $\mathrm{Y}$, maka nilai (a) dan (b) dapat ditentukan dengan cara sebagai berikut :

$$
\mathrm{a}=\frac{\left(\sum y\right)\left(\sum x^{2}\right)-\left(\sum \mathrm{x}\right) \cdot\left(\sum x \mathrm{y}\right)}{\mathrm{n} \cdot\left(\sum x^{2}\right)-\left(\sum x\right)^{2}}
$$




$$
\mathrm{b}=\frac{n \cdot(\Sigma x y)-\left(\sum \mathrm{x}\right) \cdot\left(\sum \mathrm{y}\right)}{\mathrm{n} \cdot\left(\sum x^{2}\right)-\left(\sum x\right)^{2}}
$$

d. Uji Hipotesis $(\mathrm{Uji}-t)$

Untuk menguji hipotesis yang diajukan, maka diadakan pengujian dengan menggunakan rumus " $t$ ” menurut Sugiyono (2012 : 272)yaitu :

$$
t=\frac{r \sqrt{n-2}}{\sqrt{1-r^{2}}}
$$

Degree of freedom $(\mathrm{df})=2$

Keterangan :

$\mathrm{r}=$ korelasi xy yang ditemukan

$\mathrm{n}=$ jumlah sampel

$t=t_{\text {hitung }}$ yangselanjutnya dibandingkan dengan $t_{\text {tabel }}$

Dengan taraf signifikan 0,05, uji dua arah dengan derajat kebebasan $(\mathrm{dk})=\mathrm{n}-2$.

Kriteria pengujian hipotesis sebagai berikut :

1) Apabila $t_{\text {hitung }} \geq t_{\text {tabel }}$, maka hipotesis alternatif $\left(\mathrm{H}_{\mathrm{a}}\right)$ diterima dan hipotesis nol $\left(\mathrm{H}_{\mathrm{O}}\right)$ ditolak.

2) Apabila $t_{\text {hitung }} \leq t_{\text {tabel }}$, maka hipotesis alternatif $\left(\mathrm{H}_{\mathrm{a}}\right)$ ditolak dan hipotesis nol $\left(\mathrm{H}_{\mathrm{O}}\right)$ diterima.

\section{PEMBAHASAN}

Hasil uji koefisien korelasi antara variabel penelitian diperoleh 0,63 hal ini memberi pengertian bahwa hubungan antara akuntabilitas kerja terhadap pelayananadalah kuat, hal ini sesuai dengan pendapat Sugiyono (2012:250) bahwa : "Interval koefisien antara 0,60-0,799 adalah kuat."

Sedangkan koefisien determinasi 39,69\% hal ini menunjukkan bahwa pelayanan Kartu Tanda Penduduk (KTP), Kartu Keluarga (KK) dan perizinan dapat dipengaruhi oleh akuntabilitas kerja sebesar 39,69\%. sisanya sebesar $60,31 \%$ dipengaruhi oleh faktor lain yang tidak dibahas dalam penelitian seperti fasilitas kerja, kepemimpinan dan sebagainya.

Hasil analisis regresi dengan persamaan $\mathrm{Y}=2,50+0,67 \mathrm{x}$ dapat dijelaskan konstanta sebesar 2,50 menyatakan bahwa, jika tidak ada kenaikan nilai dari variabelakuntabilitas kerja, maka nilai pelayanan adalah 2,50. Koefisien regresi sebesar 0,67x menyatakan bahwa setiap penambahan 1 (satu) skor atau nilai variabelakuntabilitas kerja akan memberikan peningkatan skor pelayanan Kartu Tanda Penduduk (KTP), Kartu Keluarga (KK) dan perizinansebesar 0,67 atau setiap variabelakuntabilitas kerjadinaikkan sebesar $100 \%$, maka pelayanan Kartu Tanda Penduduk (KTP), Kartu Keluarga (KK) dan perizinanakan meningkat sebesar $67 \%$, hal ini berlaku jika diasumsikan variabel-variabel lain dalam penelitian ini konstan atau ceteris paribus. 
Hasil uji $t$ yang diperoleh akan dibandingkan dengan harga $t_{\text {tabel }}$. Untuk kesalahan $5 \%$ uji dua pihak dan $\mathrm{dk}=\mathrm{n}-2=98$ yaitu 8,09, maka diperoleh $t_{\text {tabel }}$ $=1,980$ maka dapat dikatakan $t_{\text {hitung }}>$ dari $t_{\text {tabel }}$. Sehingga dapat ditarik kesimpulan bahwa $\mathrm{H}_{\mathrm{a}}$ diterima Ini berarti akuntabilitas kerja berpengaruh terhadap pelayanan kartu tanda penduduk (KTP), kartu keluarga (KK) dan perizinan pada Kantor Camat Badiri Kabupaten Tapanuli Tengah.

\section{KESIMPULAN DAN SARAN}

\section{A. Kesimpulan}

Berdasarkan hasil analisis dan pembahasan data yang dilakukan pada uraian sebelumnya dalam penelitian ini, dapatdiambil kesimpulan sebagai berikut :

1.Berdasarkan hasil penelitian terhadap 100 responden, menunjukkan hubungan antara akuntabilitas kerja terhadap pelayanan adalah kuat, dimana koefisien korelasi diperoleh 0,63

2.Hasil perhitungan koefisien determinasi diperoleh 39,69\% hal ini menunjukkan bahwa pelayanan Kartu Tanda Penduduk (KTP), Kartu Keluarga (KK) dan perizinan dapat dipengaruhi oleh akuntabilitas kerja sebesar 39,69\%. sisanya sebesar $60,31 \%$ dipengaruhi oleh faktor lain yang tidak dibahas dalam penelitian seperti fasilitas kerja, kepemimpinan dan sebagainya.

3.Berdasarkan model regresilinear sederhana yang diperoleh persamaan regresi adalah $\mathrm{Y}=2,50+0,67 \mathrm{x}$ menunjukkanhubungan antaraakuntabilitas kerja terhadap pelayanan kearah yang positif.

4.Berdasarkan uji $t$ diperoleh sebesar 8,09 dan $t_{\text {tabel }}=1,980$, maka dapat dikatakan $t_{\text {hitung }}>$ dari $t_{\text {tabel }}$ dapat ditarik kesimpulan bahwa $\mathrm{H}_{\mathrm{a}}$ dapat diterima.

\section{B. Saran}

Berdasarkan kesimpulan tesebut di atas, maka penulis merasa perlu memberikan saran dan masukan yang berguna untuk instansi yaitu,:

1. Hendaknya sarana dan prasarana yang ada di Kantor Camat Badiri perlu ditingkatkan serta diperhatikan perawatannya, supaya ketika dipergunakan oleh pegawai dapat bermanfaat untuk kegiatan operasional sehari-hari. Ada beberapa fasilitas yang harus diperhatikan perawatannya, misalnya meja dan kursi yang kurang layak harus dicat ulang, filling cabinet yang harus ditambah, komputer jugaharus di upgrade dan penambahan printer yang dilengkapi scanner.

2. Dalam hal ini, pemimpin juga harus memperhatikan faktor-faktor yang membuat pegawai termotivasi, baik keinginan kebutuhan maupun harapan dari masing-masing pegawai. Dengan terpenuhinya keinginan pegawai, maka otomatis para pegawai akan berusaha menampilkan kinerja yang terbaik yaitu memberikan pelayanan prima pada masyarakat.

3. Perlu ada kejelasan mengenai biaya, kepastian waktu untuk masyarakat yang ingin mendapatkan pelayanan dari Kantor Camat Badiri. Hal ini sangat penting supaya jangan ada masyarkat yang merasa diperlakukan tidak adil.

4. Perlu adanya pendidikan dan pelatihan dari pemerintah untuk aparatur untuk meningkatkan kemampuannya berorganisasi, baik itu penguatan capacity building maupun institutional building. Hal ini sangat perlu karena aparatur Kantor Camat 
merupakan ujung tombak yang terakhir yang langsung berhadapan dengan masyarakat memberi pelayanan.

5. Dari segi pelayanan publik, hal yang perlu ditingkatkan adalah kualitas yang sudah dibangun untuk menciptakan kepuasan masyarakat dipertahankan dengan sikap ramah pegawai, berpenampilan baik serta mengerti kebutuhan dan menindaklanjuti keluhan yang disampaikan oleh masyarakat. Selain itu pelayanan hendaknya dilakukan secara lebih mudah cepat dan sesuai dengan prosedur dan perundang-undangan yang berlaku.

\section{REFERENSI}

Bambang Istianto, 2009, Mewujudkan Good Governance Melalui Pelayanan Publik. Yogyakarta : UGM Press

Boediono. B, 2003, Pelayanan Prima Perpajaka,Jakarta : Rineka cipta

Gambir Bhatta, 2006,Capacity Building at the Local Level for Effective Governance, Empowerment without Capacity is Meaningless

Handayaningrat, 2009, Peranan Aparatur Pemerintah. Jakarta : Sinar Harapan

Koesoemaatmadja, 2009,Mewujudkan Good Governance Melalui Pelayanan Publik. Yogyakarta:Pustaka Pelajar

Miriam Budiarjo, 2010,Etika Administrasi Negara. Edisi. Ketiga, Cetakan Kedua Belas. Jakarta : Raja Grafindo Persada

Keputusan Menteri PAN Nomor. 63/KEP/M.PAN/8/2013 tentang Petunjuk Teknis Akuntabilitas dan Transparansi Dalam Penyelenggaraan Pelayanan Publik.

Siagian, Sondang P, 2007, Teori dan Praktek Kepemimpinan, Cetakan Kelima, Jakarta : Rineka Cipta

Sianipar, J. P. G, 2001, Manajemen Pelayanan Masyarakat, Jakarta : LAN

Sinambela Lijian Poltak, 2006, Kebijakan dan Implementasi, Reformasi Pelayanan Publik, Jakarta: Bumi Aksara

Saparin, 2006, Peranan Aparatur Pemerintah. Jakarta : Sinar Harapan

Sugiyono, 2005, Metode Penelitian Bisnis, Cetakan Ketujuh, Bandung : Alfabeta

STIE Al-Washliyah Sibolga/Tapanuli Tengah, 2015, Pedoman Penulisan dan Penyusunan Skripsi, Sibolga

The Liang Gie, 2008,Pertumbuhan Pemerintahan Daerah di Negara Republik Indonesia.Jakarta : Gunung Agung 


\section{JESYA}

JURNAL EKONOMI \& EKONOMI SYARIAH

Jurnal Ekonomi \& Ekonomi Syariah Vol 1 No 1 Januari 2018

E-ISSN 2599-3410 | P-ISSN : 2614-3259

Tingkilisan Hessel S, 2005, Manajemen Pelayanan Publik, Jakarta: Grassindo

Zauhar, 2006, Hukum Administrasi Pemerintahan di Daerah. Jakarta : Sinar Grafika. 